\title{
The survival of Haemophilus influenzae and pneumococci in specimens of sputum sent to the laboratory by post
}

\author{
J. ROBERT MAY AND DOREEN M. DELVES
}

From the Institute of Diseases of the Chest, Brompton, London

SYNOPSIS The isolation rates of $H$. influenzae and pneumococci from fresh specimens of sputum are compared with those from samples sent to the laboratory by post. The rate for both organism\$ from postal specimens is found to be approximately one half of that from fresh ones. The finding that postal specimens tend to be more acid than fresh ones does not seem to bear significantly orf the survival of organisms.

The examination of three fresh specimens from each patient, instead of a single sample, increases the isolation rate of $\mathrm{H}$. influenzae from $40 \%$ to $70 \%$ in patients with pus in the sputum. The rate for pneumococci is increased from $32 \%$ to $41 \%$. The corresponding increases in mucoid sputumb are from $15 \%$ to $23 \%$ for $H$. influenzae and from $15 \%$ to $34 \%$ for pneumococci.

The despatch of specimens of sputum by post to the laboratory for examination for $M$. tuberculosis is a time-honoured procedure, and within reason, the time lapse between expectoration and inoculation of the culture medium does not appear to affect the chance of isolating this organism. The investigation reported here was planned to determine the ability of Haemophilus influenzae and pneumococci to survive under these conditions; study of the bacteriology of the sputum of patients with chronic bronchitis would in many instances be greatly simplified if samples could be sent by post. The investigation was carried out in conjunction with the third trial of prophylactic chemotherapy in chronic bronchitis conducted by the British Tuberculosis Association. The full report of this trial will be published elsewhere.

\section{MATERIAL AND METHOD}

The difficulties inherent in an investigation of this sort pertain to the sampling errors involved in the culture of sputum (May, 1953). Not only is the distribution of organisms within individual samples often not uniform, but also there is frequently a difference in the flora of separate specimens from a given patient. The simplest way to investigate the present problem would be to make a culture from a fresh specimen of sputum and then to repeat it after 24 hours' incubation at room temperature. Unfortunately, owing to the irregularity of organisms within the sputum, it is necessary to homogenize it, by

Received for publication 5 December 1963. the action of pancreatin, before making a culture (Rawlins, 1953). The product is no longer 'sputum' anch cultures from it at a later date cannot validly be compare with one made immediately after homogenization.

An alternative possibility, namely, the division of the sputum specimen into two portions, one to be cultured immediately and the other after 24 hours, is also unsatis=factory, owing to the possibility of uneven distribution of organisms between the two halves of the specimen. If very large number of patients were available these sampling errors could no doubt be evaluated statisticallyo and an appropriate allowance made in the analysis. How ever, the circumstances of the trial, within the framework of which the present investigation was conducted, did not provide adequate material for this purpose; accordingly the method described below was used. While it would have been possible to substitute for the postal specimen? one kept at room temperature for 24 hours, it seemes. preferable that a truly 'postal' sample should be investin gated, in order that unknown factors, such as changing temperature conditions, which might be important, should not inadvertently be excluded.

The patients were men with chronic bronchitis attend ${ }_{0}^{\omega}$ ing 13 chest clinics in or near London.

COLLECTION OF SPUTUM SAMPLES Each patient was supplied with four $1 \mathrm{oz}$. screw-capped glass jars (Universal containers), in which he placed the first four pieces of sputum expectorated on a pre-determined day. Three of the samples were delivered on the same day to the patient's chest clinic and thence to the bacteriolog laboratory at the Institute of Diseases of the Chest. The fourth was sent by post to the laboratory in a cardboard carton supplied for the purpose. The time lapse betwee 
expectoration and making the culture was four to eight hours for 'fresh' specimens and 24 to 30 hours for 'postal' ones.

SPUTUM EXAMINATION Purulence was assessed by nakedeye inspection and graded in the manner described by May and May (1963). The categories recognized were: Mucopurulent $(\mathbf{M P})+++, \mathbf{M P}++, \mathbf{M P}+, \mathbf{M P} \pm$, mucoid (M).

Cultures were made on blood agar after preliminary liquefaction by pancreatin (Rawlins, 1953). $H$. influenzae and pneumococci were identified by appropriate diagnostic tests.

MEASUREMENT OF PH OF SPUTUM The $p \mathrm{H}$ of each specimen was measured with a glass electrode. Owing to the unhomogenous nature of the sputum the mean of several measurements was taken for each specimen, although in fact very little variation was observed in different parts of the sample.

\section{RESULTS}

Not every patient was able to provide all the specimens of sputum required. The isolation of $H$. influenzae and pneumococci from the ones available are shown in Table I, which indicates the higher prevalence of both organisms in mucopurulent, compared with mucoid, sputum. The table also shows that pus was present rather less frequently in the postal specimens than in the fresh ones, and this difference might be expected to result in a lower incidence of both organisms in postal specimens. The probability that the difference occurred by chance, however, is about 1 in 2 , and the sample may be taken as random for purposes of statistical analysis.

The total carrier rates (mucopurulent and mucoid sputa combined) are shown in Table II, in which the rates for postal and fresh specimens are compared. Although the difference is not always statistically significant, the isolation rates of both $H$. influenzae and pneumococci were substantially lower from postal samples. In fact both organisms were found
TABLE II

ISOLATION RATES OF H. INFLUENZAE AND PNEUMOCOCCI FROM FRESH SPECIMENS OF SPUTUM AND SPECIMENS SENT BY POST (PURULENT AND MUCOID SPECIMENS COMBINED)

\begin{tabular}{lcll}
$\begin{array}{l}\text { Specimen } \\
\text { of Sputum }\end{array}$ & $\begin{array}{l}\text { Number of } \\
\text { Specimens }\end{array}$ & $\begin{array}{l}\text { H. influenzae } \\
\text { Isolated }\end{array}$ & $\begin{array}{l}\text { Pneumococcus } \\
\text { Isolated }\end{array}$ \\
\hline First fresh & 122 & $30(25 \%) \mathbf{P}=0.02^{1}$ & $26(21 \%)$ \\
Second fresh & 115 & $29(25 \%) \mathbf{P}=0.02$ & $27(23 \%)$ \\
Third fresh & 107 & $21(20 \%)$ & $28(26 \%) \mathrm{P}<0.05$ \\
Postal & 102 & $13(13 \%)$ & $14(14 \%)$
\end{tabular}

${ }^{1}$ The probabilities shown indicate the statistical significance of the difference between the relevant fresh specimens and the postal specimen. Where no probability is shown the difference was not significant $(\mathrm{P}>0.05)$.

about half as frequently in these as in fresh specimens. Differences observed between the individual fresh specimens are not significant.

It is, of course, still possible that the differences observed between the isolation rates in postal specimens and those in fresh ones were due to chance variations in the distribution of organisms. The statistical observations already noted suggest that this was not so, but it was felt that further evidence was desirable. The isolation rates of organisms from the postal and first fresh specimens from individual patients, therefore, were compared and the results are shown in Table III. If the differences between the two specimens were the result of chance variation alone, then there should be no difference between columns 2 and 3 in Table III. In fact, with both organisms, there was a significant difference $(P \fallingdotseq$ 0.02 in each case) between the number of times the fresh specimen was positive and the postal one negative and vice versa. Although column 3 indicates that chance variations did occur, clearly some other factor was much more important in reducing the isolation rates of both organisms in the postal specimens.

In passing, it is of interest to note the remarkable increase in isolation rates per patient brought about by the examination and pooling of the findings of three fresh specimens compared with only one. The

TABLE I

ISOLATION RATES OF $H$. INFLUENZAE AND PNEUMOCCOCI FROM FRESH SPECIMENS OF SPUTUM AND SPECIMENS SENT BY POST

\begin{tabular}{|c|c|c|c|c|}
\hline $\begin{array}{l}\text { Specimen } \\
\text { of Sputum }\end{array}$ & $\begin{array}{l}\text { Character } \\
\text { of Sputum }\end{array}$ & $\begin{array}{l}\text { Number of } \\
\text { Specimens }\end{array}$ & $\begin{array}{l}\text { H. influenzae } \\
\text { Isolated }\end{array}$ & $\begin{array}{l}\text { Pneumococcus } \\
\text { Isolated }\end{array}$ \\
\hline First fresh & $\begin{array}{l}\text { Mucopurulent } \\
\text { Mucoid }\end{array}$ & $\begin{array}{l}47 / 122^{1}(39 \%) \\
75 / 122(61 \%)\end{array}$ & $\begin{array}{l}19 / 47(40 \%) \\
11 / 75(15 \%)\end{array}$ & $\begin{array}{l}15 / 47(32 \%) \\
11 / 75(15 \%)\end{array}$ \\
\hline Second fresh & $\begin{array}{l}\text { Mucopurulent } \\
\text { Mucoid }\end{array}$ & $\begin{array}{l}42 / 115(37 \%) \\
73 / 115(63 \%)\end{array}$ & $\begin{array}{r}20 / 42(47 \%) \\
9 / 73(12 \%)\end{array}$ & $\begin{array}{l}12 / 42(29 \%) \\
15 / 73(21 \%)\end{array}$ \\
\hline Third fresh & $\begin{array}{l}\text { Mucopurulent } \\
\text { Mucoid }\end{array}$ & $\begin{array}{l}41 / 107(38 \%) \\
66 / 107(62 \%)\end{array}$ & $\begin{array}{c}15 / 41(37 \%) \\
6 / 66(9 \%)\end{array}$ & $\begin{array}{l}14 / 41(34 \%) \\
14 / 66(21 \%)\end{array}$ \\
\hline Postal & $\begin{array}{l}\text { Mucopurulent } \\
\text { Mucoid }\end{array}$ & $\begin{array}{l}34 / 102(33 \%) \\
68 / 102(67 \%)\end{array}$ & $\begin{array}{l}8 / 34(24 \%) \\
5 / 68(7 \%)\end{array}$ & $\begin{array}{l}8 / 34(24 \%) \\
6 / 68(9 \%)\end{array}$ \\
\hline
\end{tabular}

${ }^{1}$ The denominator of each fraction indicates the number in the group; the numerator indicates the number giving a positive result. 
TABLE III

COMPARISON OF ISOLATION RATES OF H. INFLUENZAE AND PNEUMOCOCCI IN 'FIRST FRESH' AND THE 'POSTAL' SPECIMENS OF SPUTUM FROM INDIVIDUAL PATIENTS

Organism No. of Patients with Bacterial Isolations Total Patients

\begin{tabular}{|c|c|c|c|c|c|}
\hline & $\begin{array}{c}1 \text { Fresh + } \\
\text { Postal + }\end{array}$ & $\begin{array}{c}2 \text { Fresh }+ \\
\text { Postal - }\end{array}$ & $\begin{array}{l}3 \text { Fresh - } \\
\text { Postal + }\end{array}$ & $\begin{array}{l}4 \text { Fresh }- \\
\text { Postal - }\end{array}$ & \\
\hline H. influenzae & 6 & 17 & 6 & 68 & 97 \\
\hline Pneumococcus & 4 & 19 & 8 & 66 & 97 \\
\hline
\end{tabular}

rate for $\mathrm{H}$. influenzae in mucopurulent sputum rose from $40 \%$ to $70 \%$ and in mucoid sputum from $15 \%$ to $23 \%$ (figures not shown in tables). The corresponding rises for pneumococci were from $32 \%$ to $41 \%$ and from $15 \%$ to $34 \%$. Unfortunately, comparable figures for the results of three pooled postal specimens are not available.

SIGNIFICANCE OF THE PH OF SPUTUM Earlier observations indicated that the $p \mathrm{H}$ of sputum might vary widely, and in this investigation the possible bactericidal significance of divergence from neutral was studied. Measurements were made in 118 fresh specimens expectorated first thing in the morning, 144 second specimens, 99 third specimens, and 104 specimens sent to the laboratory by post. The results are shown in Figure 1.

The degree of scatter about the mean is approximately equal for each type of specimen, but it is noticeable that the postal samples showed a tendency towards greater acidity than the fresh ones. This acidity was associated to some extent with purulence of the sputum: each of two specimens with a $p \mathrm{H}$ of 4.0 to 4.4 was graded MP+; of five specimens with a $p \mathrm{H}$ of 4.5 to 4.9 , one was graded MP +++ , three were MP+, and only one was mucoid; and of four specimens with a $p \mathrm{H}$ of 5.0 to 5.4 , one was $\mathrm{MP}+++$, two were $\mathbf{M P}+$, and one was mucoid.

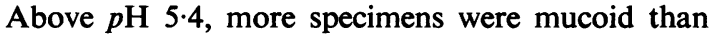
mucopurulent. In contrast, the number of fresh specimens with a $p \mathrm{H}$ less than 5.5 was very small and there was no detectable trend towards association of acidity with purulence.
Owing to the very small numbers of specimens in the $p \mathrm{H}$ groups on either side of the mean, analysis of the isolation rates of $H$. influenzae and pneumococci in the groups has little value. It is possible, however, to determine their prevalence in pooled groups above and below an arbitrary reference level, and thus to determine whether or not the acidity of $\stackrel{N}{A}$ the sputum can be correlated with survival of 을 organisms. In fact by this method the only correlation demonstrable relates to the isolation rate of $\bar{z}$ pneumococci in postal specimens, taking $p \mathrm{H} 6.5$ as the reference level. The organisms were found in $14 \% \vec{~}$ of 62 samples with a $p \mathrm{H}$ measurement of 6.5 or higher compared with only $7 \%$ of 42 samples with a $p \mathrm{H}$ of 6.4 or lower. This difference is not statistically significant, however, and must be considered to indicate only a trend. No such trends could be demonstrated for $\boldsymbol{H}$. influenzae nor for pneumococci in respect of other $p \mathrm{H}$ reference levels, and one must conclude, therefore, that $p \mathrm{H}$ is unlikely to exert more than a minor influence on the survival of these organisms.

We wish to express our thanks to the Research Committee of the British Tuberculosis Association for permission to publish this paper, to Brian Gibbins for technical assistance, and to the physicians who cooperated by sending specimens.

\section{REFERENCES}

May, J. R. (1953). Lancet, 2, 534.

May, J. R. (1950), D. S. (1963). Tubercle (Edinb.), 44, 162. Rawlins, G. A. (1953). Lancet, 2, 538.

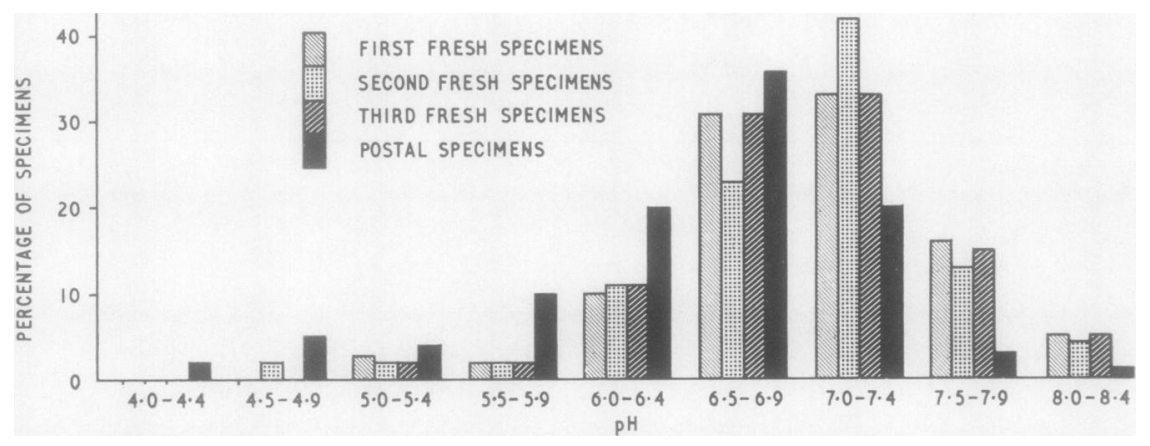

FIG. 1. Measurements of $\mathrm{pH}$ in $\stackrel{\infty}{+}$ various specimens of $\mathrm{T}$ sputum. 